\title{
Cyclotetrabenzil-Based Porous Organic Polymers with High Carbon Dioxide Affinity
}

\author{
Timur Ashirov ${ }^{\mathrm{a}}$ (D) \\ Maymounah Alrayyani ${ }^{\text {b,c (D) }}$ \\ Kyung-Seob Song ${ }^{a}$ \\ Ognjen Š. Miljanić*c (iD) \\ Ali Coskun*a (i)

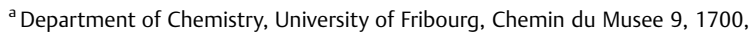 \\ Fribourg, Switzerland \\ ${ }^{b}$ Chemistry Department, Faculty of Science, King Abdulaziz University, Jeddah 23218 , \\ Saudi Arabia \\ 'Department of Chemistry, University of Houston, 3585 Cullen Boulevard \#112, \\ Houston, TX 77204-5003, United States \\ miljanic@uh.edu; ali.coskun@unifr.ch
}

Received: 15.03 .2021

Accepted after revision: 25.04.2021

DOI: 10.1055/a-1512-5753; Art ID: om-21-0025oa

License terms: (C)

(c) 2021. The Author(s). This is an open access article published by Thieme under the terms of the Creative Commons Attribution-NonDerivative-NonCommercial License, permitting copying and reproduction so long as the original work is given appropriate credit. Contents may not be used for commercial purposes, or adapted, remixed, transformed or built upon. (https://creativecommons.org/licenses/by-nc-nd/4.0/)

Abstract Porous organic polymers (POPs) incorporating macrocyclic units have been investigated in recent years in an effort to transfer macrocycles' intrinsic host-guest properties onto the porous networks to achieve complex separations. In this regard, highly interesting building blocks are presented by the family of cyclotetrabenzoin macrocycles with rigid, well-defined, electron-deficient cavities. This macrocycle shows high affinity towards linear guest molecules such as carbon dioxide, thus offering an ideal building block for the synthesis of $\mathrm{CO}_{2}$-philic POPs. Herein, we report the synthesis of a POP through the condensation reaction between cyclotetrabenzil and 1,2,4,5-tetraaminobenzene under ionothermal conditions using the eutectic zinc chloride/sodium chloride/potassium chloride salt mixture at $250{ }^{\circ} \mathrm{C}$. Notably, following the condensation reaction, the macrocycle favors three-dimensional (3D) growth rather than a two-dimensional one while retaining the cavity. The resulting polymer, named 3D-mPOP, showed a highly microporous structure with a BET surface area of $1142 \mathrm{~m}^{2} \mathrm{~g}^{-1}$ and a high carbon dioxide affinity with a binding enthalpy of $39 \mathrm{~kJ} \mathrm{~mol}^{-1}$. Moreover, 3D-mPOP showed very high selectivity for carbon dioxide in carbon dioxide/methane and carbon dioxide/nitrogen mixtures.

Key words macrocycles, porous polymers, host-guest chemistry, ionothermal synthesis, $\mathrm{CO}_{2}$ capture

\section{Introduction}

The environmental impact of greenhouse gas emissions is an ever-growing concern, primarily due to the continuously rising atmospheric levels of carbon dioxide $\left(\mathrm{CO}_{2}\right)$,

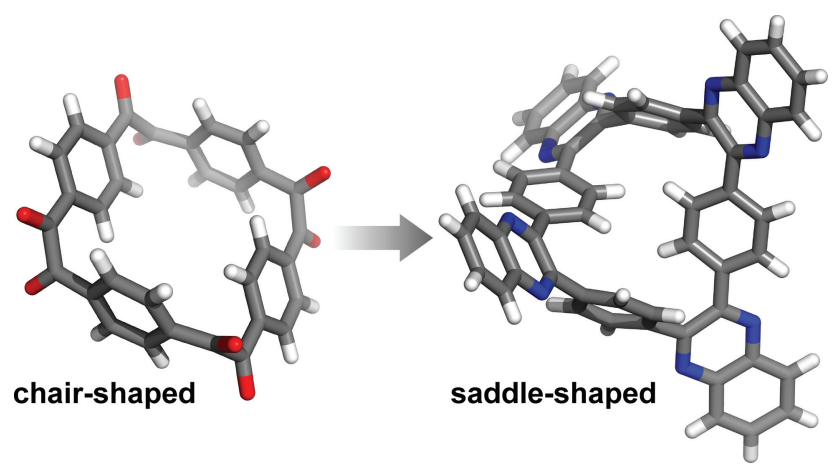

which have surpassed 400 ppm. ${ }^{1}$ In addition to lowering the world's reliance on fossil fuel energy, ${ }^{2}$ technologies to capture $\mathrm{CO}_{2}$ will be needed to minimize the environmental impact of this gas. In this regard, porous materials have gained tremendous attention. Light-weight porous organic polymers (POPs) with high surface areas, structural tunability, chemical stability, scalability and ease of preparation are intriguing candidates to tackle this problem. ${ }^{3}$ The $\mathrm{CO}_{2}$ affinity of a POP is determined by two main parameters: (a) the size of the pores, which should be in the ultramicropore ( $\sim 0.7 \mathrm{~nm})$ to micropore range $(<2 \mathrm{~nm})$ and (b) the presence of heteroatoms such as nitrogen that can enhance dipole-quadrupole interactions with $\mathrm{CO}_{2} .{ }^{4}$ Shapepersistent macrocycles and cages can offer well-defined binding sites for $\mathrm{CO}_{2}$ molecules and facilitate its efficient capture and separation. ${ }^{5}$ In this direction, POPs containing macrocycle or cage-building blocks have gained significant interest in recent years and have already found applications in water/air purification, ${ }^{6}$ natural gas purification, ${ }^{3 \mathrm{~d}, 7}$ adsorption of toxic pollutants ${ }^{8}$ and as battery electrodes. ${ }^{9}$ The macrocycles including cyclodextrins, calix[4]arenes, resorarenes, and pillar[5]arenes have already been integrated into the POPs. ${ }^{10}$ Recently, Miljanić and coworkers reported a facile and a scalable approach for the preparation of cyclotetrabenzoin macrocycles and their esters. ${ }^{11}$ Cyclotetrabenzoin esters feature a well-defined, electron-deficient cavity, which is shown to be selective towards linear guest molecules such as terminal alkynes, organic nitriles, ${ }^{12}$ $\mathrm{CS}_{2}$, and $\mathrm{CO}_{2},{ }^{13}$ and a surface area greater than $500 \mathrm{~m}^{2} \mathrm{~g}^{-1}$ in the case of cyclotetrabenzoin acetate. It has also been reported that larger guests such as benzonitrile and phenyl acetylene do not fit in the cavity. ${ }^{12}$ The oxidation of cyclotetrabenzoin to the corresponding octaketone dubbed cyclotetrabenzil (labeled as octaketone in Scheme 1a) enabled further derivatization through a condensation reaction with 1,2-phenylenediamines to form pyrazine linkages. Interestingly, whereas the acetylated 


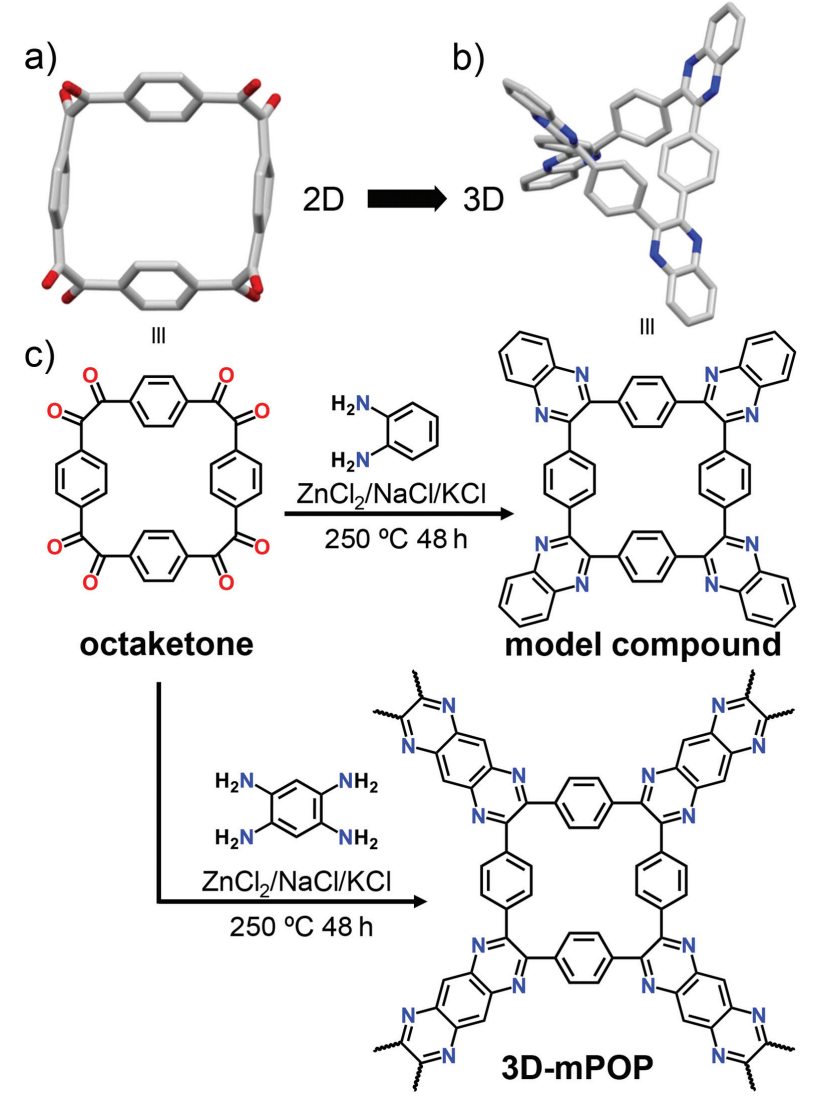

Scheme 1 Single-crystal XRD structure of the a) octaketone, b) model compound (adapted with permission from Ref. 14. Copyright 2017 Wiley- $\mathrm{VCH}$ ). c) Synthetic scheme and the chemical structures of the model compound and 3D-mPOP.

cyclotetrabenzoin largely retains the square-grid structure of the parent cyclotetrabenzoin, steric hindrance generated by pyrazine linkages forced the macrocycle to adopt a saddle-shaped three-dimensional (3D) structure, with pyrazine linkages arranged in an alternating manner, thus offering a unique platform for the synthesis of fully $\mathrm{sp}^{2}$ hybridized 3D-POPs. ${ }^{15}$

\section{Results and Discussion}

The cyclotetrabenzoin itself is highly insoluble due to the strong intermolecular hydrogen bonding interactions. ${ }^{15 \mathrm{~b}}$ Upon its treatment with nitric acid, it is oxidized to the corresponding cyclotetrabenzil octaketone, which has a much higher solubility as it is no longer a hydrogen bond donor. ${ }^{14}$ The X-ray diffraction (XRD) crystal structure of octaketone shows a geometry that resembles a chair. One pair of rings is facing each other, with an interplanar distance of $7.64 \AA$, while the other pair finds themselves in parallel planes (interplanar distance: $4.23 \AA$ ) but offset from each other. The neighboring carbonyl groups are almost perpendicular to each other, with $\mathrm{O}=\mathrm{C}-\mathrm{C}=\mathrm{O}$ dihedral angles of $82.1^{\circ}$ and $88.3^{\circ}$. In the extended packing diagram of this compound, noticeable are short $(2.34 \AA)$ contacts between carbonyl oxygens on one molecule and aromatic hydrogens on the neighboring molecule. The condensation reaction between octaketone and 1,2-phenylenediamine in ethanol affords the corresponding pyrazine-functionalized model compound, whose structure is highly distorted into a 3D structure resembling a saddle, as evidenced from the singlecrystal X-ray structure. Within the central macrocycle, one pair of aromatic planes is almost parallel $\left(7.2^{\circ}\right.$ interplanar angle), while the other shows significant twisting with an interplanar angle of $80.6^{\circ}$. The planes of the appended quinoxaline moieties on the opposite sides of this model compounds form a V-shape with interplanar angles of $69.7^{\circ}$ and $73.8^{\circ}$.

There are only a handful of fully $\mathrm{sp}^{2}$-hybridized organic linkers (such as e.g. cyclooctatetraene), which are at the same time synthetically accessible and deplanarized enough to offer a 3D arrangement, though none of these linkers features an intrinsic pore. Inspired by these results, we targeted the synthesis of a macrocycle-containing 3D POP, 3D-mPOP, by reacting octaketone with 1,2,4,5-tetraaminobenzene under ionothermal conditions using a $\mathrm{ZnCl}_{2} / \mathrm{KCl} / \mathrm{NaCl}$ eutectic salt mixture (Scheme 1c) at $250^{\circ}$ $\mathrm{C}^{16}$ Since the eutectic salt mixture has a lower melting point than $\mathrm{ZnCl}_{2}$, it enables the polymerization reaction to proceed at lower temperatures, which is critical to avoid partial carbonization. The formation of 3D-mPOP was verified by Fourier-transform infrared (FTIR) and X-ray photoelectron spectroscopy (XPS) analyses (Figure 1a, b). FTIR spectra revealed the formation of pyrazine linkages as evidenced by the $\mathrm{C}=\mathrm{N}$ stretching band at $1669 \mathrm{~cm}^{-1}$. We also observed a residual $\mathrm{C}=0$ stretching at $1696 \mathrm{~cm}^{-1} \cdot{ }^{17}$ The $-\mathrm{NH}_{3}{ }^{+}$stretching band of 1,2,4,5-tetraaminobenzene tetrahydrochloride (TABH) at $2466 \mathrm{~cm}^{-1}$ also disappeared, further indicating the successful formation of pyrazine linkages. We also observed the characteristic aromatic $=\mathrm{C}-\mathrm{H}$ stretching and bending modes at 3000 and $1413 \mathrm{~cm}^{-1}$, respectively (Figure 1a). The XPS N1s spectrum revealed the $-\mathrm{C}-\mathrm{N}-$ and $-\mathrm{C}=\mathrm{N}-$ peaks at 398.8 and $400.2 \mathrm{eV}$, respectively, which were in a perfect agreement with those of pyrazine moieties. ${ }^{18}$ Moreover, the $\mathrm{C} 1 \mathrm{~s}$ spectrum revealed three different carbon binding energies at 284.5, 285.5 and $286.8 \mathrm{eV}$, representing the characteristic $-\mathrm{C}-\mathrm{C}-/-\mathrm{C}=\mathrm{C}-$, $-\mathrm{C}-\mathrm{N}-$, and $-\mathrm{C}=\mathrm{N}-$ signatures, respectively (Figure $1 \mathrm{~b}) .{ }^{19}$ As a control sample, the model compound was synthesized under the same reaction conditions by reacting octaketone with 1,2-diaminobenzene in an $85 \%$ yield (see Figure S1 for the characterization data). ${ }^{14}$ The powder XRD analysis of the $3 \mathrm{D}-\mathrm{mPOP}$ revealed its amorphous nature (Figure S2). In addition, the chemical structure of the 3D-mPOP was verified by solid-state cross-polarization magic-angle 

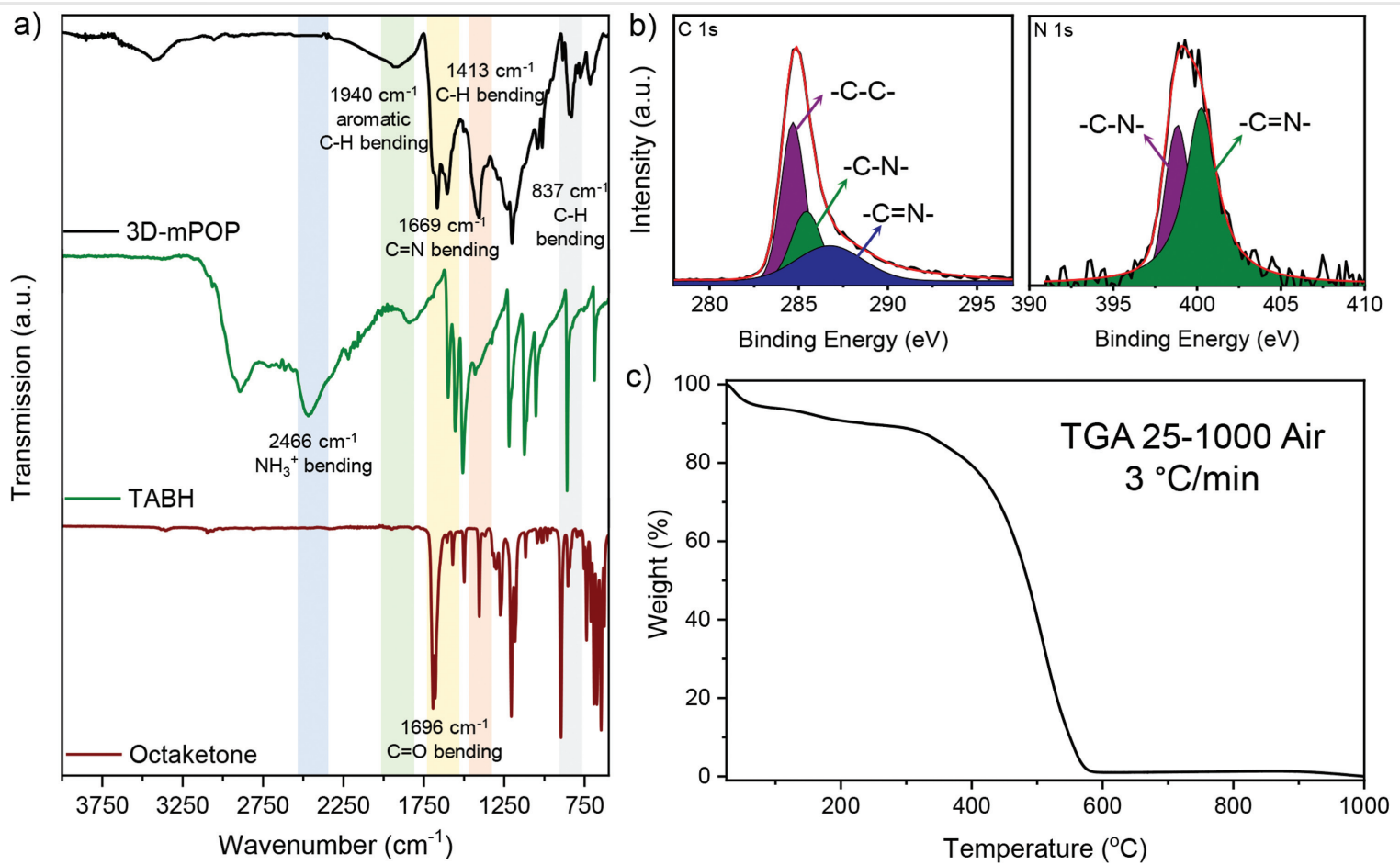

Figure 1 a) FTIR spectra of the 3D-mPOP and starting materials; octaketone and TABH for comparison, b) C 1s and N 1s XPS spectrum of 3D-mPOP, c) TGA curve of the 3D-mPOP measured under air.

spinning ${ }^{13} \mathrm{C}$ NMR analysis. The solid-state ${ }^{13} \mathrm{C}$ NMR spectrum of 3D-mPOP is (Figure S3) found to be in good agreement with that of the model compound. In line with the FTIR data, we observed the presence of terminal carbonyl moieties at $194 \mathrm{ppm}$. Elemental analysis (EA) was performed to determine the elemental composition of 3D-mPOP (Table S1). The EA data showed $76.7 \%$ of $\mathrm{C}, 14.8 \%$ of $\mathrm{N}$ and $5.2 \%$ of $\mathrm{H}$, in good agreement with the calculated data. We attributed the slight deviation in the $\mathrm{C}$ and $\mathrm{N}$ contents to the presence of water molecules trapped within the pores, as verified by the presence of a broad peak at $3300 \mathrm{~cm}^{-1}$ in the FTIR spectrum (Figure 1a). Thermogravimetric analysis (TGA) data showed that the synthesized polymer is stable up to $350{ }^{\circ} \mathrm{C}$ under both air (Figure 1c) and $\mathrm{N}_{2}$ (Figure S4) atmosphere. The initial mass loss is attributed to the removal of trapped solvents and water. Complete removal of the salts can be verified by TGA under air where $100 \%$ mass loss is obtained at $1000{ }^{\circ} \mathrm{C}$ (Figure 1c).

The porosity and pore structure of 3D-mPOP and the model compound were analyzed with $\mathrm{N}_{2}$ sorption measurements at $77 \mathrm{~K}$ (Figure 2a). The surface area was calculated from adsorption isotherms using the Brunauer-EmmettTeller (BET) theory ${ }^{20}$ and the pressure ranges were determined from the Rouquerol plots (Figure S5). 3DmPOP showed a Type I isotherm showing a highly microporous structure. On the contrary, the model com- pound showed a Type III adsorption isotherm indicating a nonporous or macroporous structure (Figure 2a). While 3DmPOP has a BET surface area of $1142 \mathrm{~m}^{2} \mathrm{~g}^{-1}$, that of the model compound was found to be only $31 \mathrm{~m}^{2} \mathrm{~g}^{-1}$ (Figure 2a and Table 1). The scanning electron micrographs (SEMs) revealed an interconnected pore structure presumably due to the templating effect of the salts ${ }^{16,21}$ (Figure S6). The nonlocal density functional theory (NLDFT) pore size distribution analysis showed the presence of two types of micropores with respective sizes of 5.4 and $11.4 \AA$ (Figure 2b). The $5.4 \AA$-sized pore corresponds to the center of the distorted pyrazine-based macrocycle cavity and the $11.4 \AA$ sized pore corresponds to the extrinsic pores formed after the polymerization. The $\mathrm{H} 4$ hysteresis in the desorption branch at $P / P_{0}=0.4$ points to the presence of mesopores and a slit-like pore structure. ${ }^{22}$

The microporous structure of 3D-mPOP was further examined by $\mathrm{CO}_{2}, \mathrm{CH}_{4}$, and $\mathrm{N}_{2}$ uptake (Figure $2 \mathrm{c}$ ) experiments. The $\mathrm{CO}_{2}$ gas uptake at $273 \mathrm{~K}$ was found to be $2.29 \mathrm{mmol} \mathrm{g}^{-1}$, followed by $0.51 \mathrm{mmol} \mathrm{g}^{-1}$ for $\mathrm{CH}_{4}$, and almost no uptake of $\mathrm{N}_{2}\left(0.14 \mathrm{mmol} \mathrm{g}^{-1}\right)$. These results clearly demonstrate (Table 2 ) the $\mathrm{CO}_{2}$-philicity of the $3 \mathrm{D}$ mPOP, which is likely arising from the cyclotetrabenzoin macrocycle, which was shown to be a good host for the various linear molecules including $\mathrm{CO}_{2} \cdot{ }^{11,13}$ The isosteric heat of adsorption $\left(Q_{\mathrm{st}}\right)$ for $\mathrm{CO}_{2}$ was calculated from the 

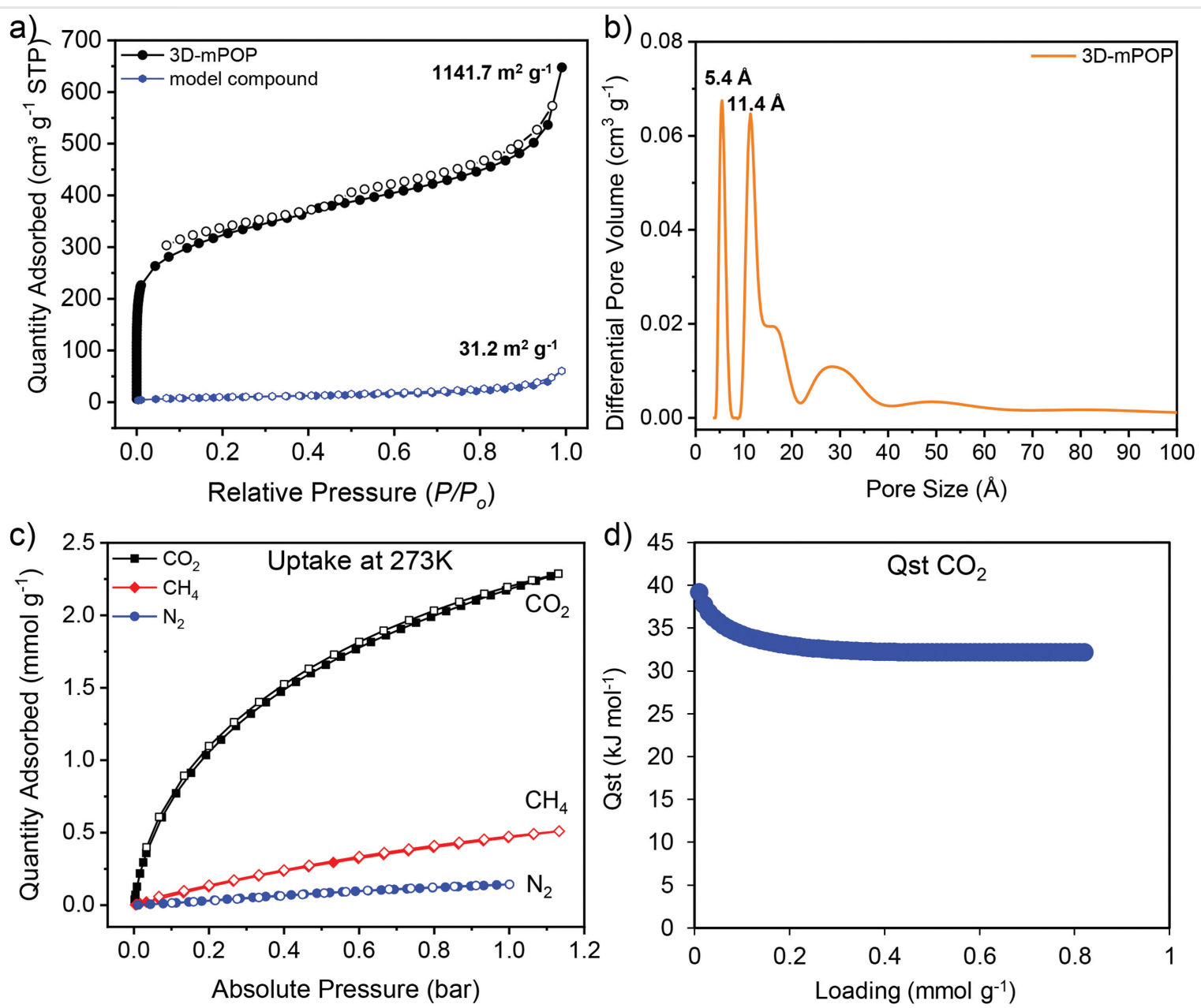

Figure 2 a) $\mathrm{N}_{2}$ adsorption-desorption isotherms of 3D-mPOP and model compound measured at $77 \mathrm{~K}$. b) NLDFT pore size distribution vs. pore volume of 3D-mPOP, c) $\mathrm{CO}_{2}, \mathrm{CH}_{4}$ and $\mathrm{N}_{2}$ uptake isotherms of 3D-mPOP obtained at $273 \mathrm{~K}$. d) The $\mathrm{CO}_{2}$ isosteric heat of adsorption ( $\left.Q_{s t}\right)$ plot of 3D-mPOP. Filled and empty symbols represent adsorption and desorption branches, respectively.

Table $1 \mathrm{~N}_{2}$ adsorption-desorption analysis results of the model compound and 3D-mPOP at $77 \mathrm{~K}$

\begin{tabular}{lllllll}
\hline Sample & $\mathrm{BET}^{\mathrm{a}}\left(\mathrm{m}^{2} \mathrm{~g}^{-1}\right)$ & $S_{\text {micro }}{ }^{\mathrm{b}}\left(\mathrm{m}^{2} \mathrm{~g}^{-1}\right)$ & $S_{\text {ext }}{ }^{\mathrm{c}}\left(\mathrm{m}^{2} \mathrm{~g}^{-1}\right)$ & $V_{\text {total }}{ }^{\mathrm{d}}\left(\mathrm{cm}^{3} \mathrm{~g}^{-1}\right)$ & $V_{\text {micro }}{ }^{\mathrm{e}}\left(\mathrm{cm}^{3} \mathrm{~g}^{-1}\right)$ & - \\
\hline Model compound & 31 & - & - & - & - & $V_{\text {ext }}{ }^{\mathrm{f}}\left(\mathrm{cm}^{3} \mathrm{~g}^{-1}\right)$ \\
3D-mPOP & 1142 & 561 & 581 & 1.00 & 0.24 & 0.76 \\
\hline
\end{tabular}

${ }^{\mathrm{a} B E T}$ surface area calculated over the pressure range $\left(P / P_{0}\right)$ of $0.01-0.11$.

Micropore surface area calculated using the $t$-plot method.

${ }^{c} S_{\text {ext }}=S_{\text {total }}-S_{\text {micro. }}$.

${ }^{\mathrm{d}}$ Total pore volume obtained at $P / P_{0}=0.99$.

eMicropore volume calculated using the $t$-plot method.

${ }^{f} V_{\text {ext }}=V_{\text {total }}-V_{\text {micro. }}$.

adsorption isotherms obtained at 273, 298, and $323 \mathrm{~K}$ (Figure S7). ${ }^{3 \mathrm{e}}$ The $\mathrm{Q}_{\mathrm{st}}$ value for $\mathrm{CO}_{2}$ was found to be in the range of 32.2-39.2 kJ mol${ }^{-1}$ (Figure $2 \mathrm{~d}$ ), Notably, the $Q_{\mathrm{st}}$ value of $39.2 \mathrm{~kJ} \mathrm{~mol}^{-1}$ at zero coverage clearly shows that the affinity of the 3D-mPOP towards $\mathrm{CO}_{2}$ is dictated by the macrocyclic units. ${ }^{3}$ Moreover, the calculated $Q_{s t}$ value is highly favorable as the adsorption is physical, which results in easier regeneration. ${ }^{3 e}$ Given the high affinity of 3D-mPOP 
Table $2 \mathrm{CO}_{2}, \mathrm{CH}_{4}$ and $\mathrm{N}_{2}$ uptake capacities of 3D-mPOP along with the corresponding isosteric heats of adsorption $\left(Q_{\mathrm{st}}\right)$ and IAST $\mathrm{CO}_{2} /$ gas selectivities

\begin{tabular}{|c|c|c|c|c|c|c|c|c|}
\hline \multirow[b]{2}{*}{$T(\mathrm{~K})=$} & \multicolumn{4}{|c|}{$\mathrm{CO}_{2}$ uptake $\left(\mathrm{mmol} \mathrm{g}^{-1}\right)$} & \multirow{2}{*}{$\begin{array}{l}\begin{array}{l}\mathrm{CH}_{4} \text { uptake } \\
\left(\mathrm{mmol} \mathrm{g}^{-1}\right)\end{array} \\
273\end{array}$} & \multirow{2}{*}{$\begin{array}{l}\begin{array}{l}\mathrm{N}_{2} \text { uptake } \\
\left(\mathrm{mmol} \mathrm{g}^{-1}\right)\end{array} \\
273\end{array}$} & \multirow{2}{*}{$\begin{array}{l}\mathrm{CO}_{2} / \mathrm{N}_{2} \text { selectivity } \\
\text { (IAST), } 273 \mathrm{~K}^{\mathrm{b}}\end{array}$} & \multirow{2}{*}{$\begin{array}{l}\mathrm{CO}_{2} / \mathrm{CH}_{4} \text { selectivity } \\
(\mathrm{IAST}), 273 \mathrm{~K} \\
22(5: 95)\end{array}$} \\
\hline & 273 & 298 & 323 & $Q_{s t}{ }^{a}\left(\mathrm{~kJ} \mathrm{~mol}{ }^{-1}\right)$ & & & & \\
\hline 3D-mPOP & 2.29 & 1.52 & 0.82 & 39.2 & 0.51 & 0.14 & & $18(50: 50)$ \\
\hline
\end{tabular}

asosteric heats of adsorption $\left(Q_{s t}\right)$ values calculated using the gas adsorption data at 273,298 and $323 \mathrm{~K}_{\text {for }} \mathrm{CO}_{2}$ using the Clausius-Clapeyron equation. The $Q_{\mathrm{st}}$ value is reported at zero coverage.

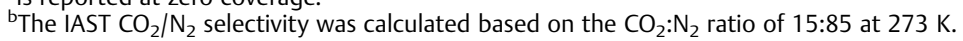

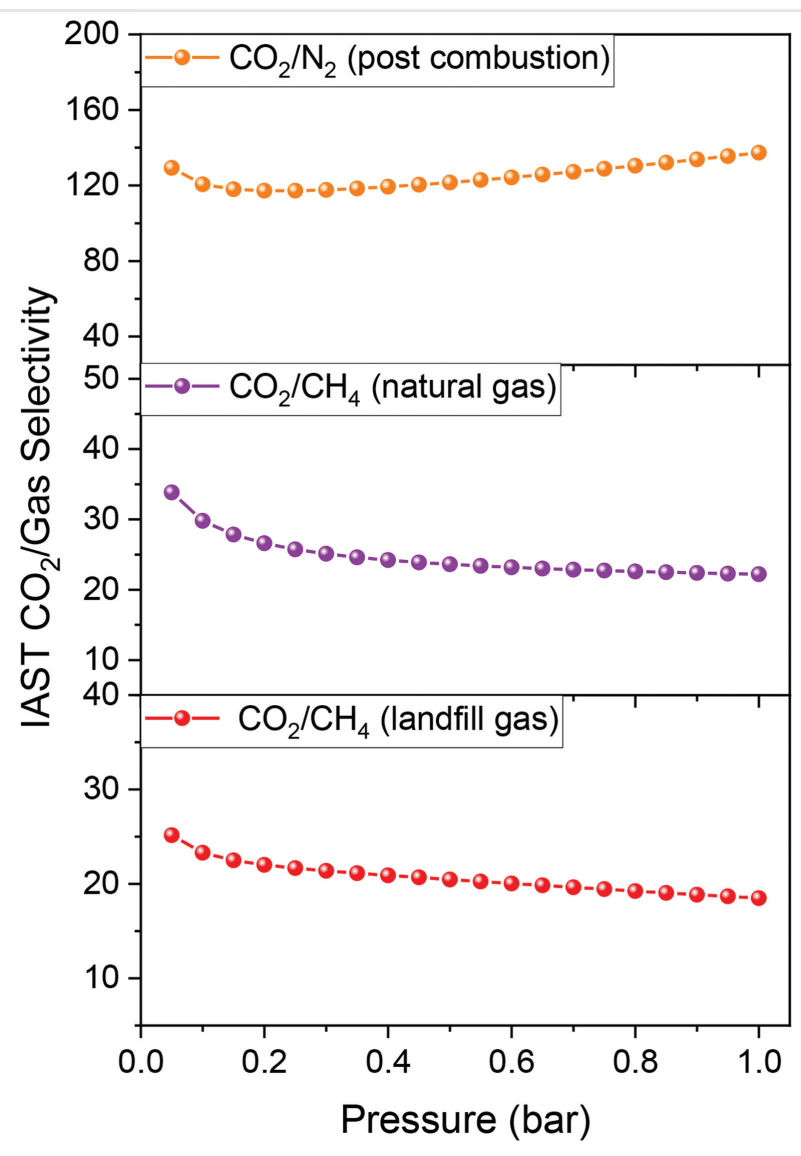

Figure 3 The IAST $\mathrm{CO}_{2} / \mathrm{N}_{2}$ and $\mathrm{CO}_{2} / \mathrm{CH}_{4}$ selectivities of the 3D-mPOP. The $\mathrm{CO}_{2} / \mathrm{N}_{2}$ selectivity was calculated using the gas ratio of $\mathrm{CO}_{2}: \mathrm{N}_{2}$ 15:85 and $\mathrm{CO}_{2}: \mathrm{CH}_{4}$ 5:95 (natural gas) and 50:50 (landfill gas).

towards $\mathrm{CO}_{2}$, we decided to evaluate the $\mathrm{CO}_{2}$ selectivity over $\mathrm{N}_{2}$ and $\mathrm{CH}_{4}$. The gas selectivity of 3D-mPOP was investigated by measuring the corresponding gas uptake isotherms at $273 \mathrm{~K}$ up to $1 \mathrm{bar}$. The initial steep increase in the case of $\mathrm{CO}_{2}$ (Figure 2c) is attributed to the high affinity of the macrocyclic units for this guests. High $\mathrm{CO}_{2}$ uptake at low partial pressures $\left(P / P_{0}=0.15\right)$ is highly relevant, especially for flue gas separation. In order to calculate the mixed gas selectivity from single-component gas adsorption isotherms, we used the ideal adsorbed solution theory
(IAST), which is quite useful to evaluate the mixed gas selectivity for various porous materials.

3D-mPOP showed an excellent $\mathrm{CO}_{2} / \mathrm{N}_{2}$ (15:85) IAST selectivity of 137 under flue gas conditions at 1 bar. We also evaluated the performance of 3D-mPOP for natural gas $\left(\mathrm{CO}_{2}: \mathrm{CH}_{4}, 5: 95\right)$ and land fill gas $\left(\mathrm{CO}_{2}: \mathrm{CH}_{4}, 50: 50\right)$ separation (for performance comparison, see Table S2). ${ }^{23}$ The IAST $\mathrm{CO}_{2} / \mathrm{CH}_{4}$ selectivities of 3D-mPOP for natural gas and land fill gas turned out to be 22 and 18, respectively (Figure 3 ) at $273 \mathrm{~K}, 1$ bar. These values are significantly higher compared to the pillar[5]arene-based polymers ${ }^{8 a}$ and comparable to the POPs incorporating highly $\mathrm{CO}_{2}$-philic organic cages. ${ }^{5 \mathrm{a}}$ Moreover, 3D-mPOP also performed better than representative POPs such as BILPs ${ }^{3 c, 24}$ and azo-COPs ${ }^{25}$ thus clearly demonstrating the impact of the macrocycle (for a detailed comparison, see Table S2). High $\mathrm{CO}_{2}$ selectivity of the 3DmPOP over $\mathrm{N}_{2}$ and $\mathrm{CH}_{4}$ is attributed to the strong affinity of the macrocycle towards the linear guest molecules as well as to the larger kinetic diameter of $\mathrm{N}_{2}\left(3.64 \AA\right.$ ) and $\mathrm{CH}_{4}$ $(3.80 \AA)$ compared to $\mathrm{CO}_{2}(3.30 \AA)$. These values clearly demonstrate the potential of 3D-mPOP for $\mathrm{CO}_{2}$ removal from landfill gas and natural gas mixtures as well as $\mathrm{CO}_{2}$ scrubbing.

\section{Conclusions}

We demonstrated the potential of cyclotetrabenzil as a functional organic building block to form fully $\mathrm{sp}^{2}$ hybridized 3D polymer networks. Moreover, the high apparent affinity of the cyclotetrabenzil host towards the linear guest molecules was successfully transferred to the polymer network to achieve highly efficient $\mathrm{CO}_{2}$ capture, with high selectivity over $\mathrm{N}_{2}$ and $\mathrm{CH}_{4}$. This study also underlines the potential of macrocycles and cages as building blocks for the synthesis of POPs for complex separations thanks to their highly selective host-guest interactions.

\section{Experimental Section}

All the chemicals and solvents were used as purchased without any further purification. Dry solvents were 
purchased from Sigma-Aldrich or Acros Chemicals. The $\mathrm{NaCl}$ (99.95\%) and $\mathrm{KCl}$ (99.95\%) were purchased from Carl-Roth. The $\mathrm{ZnCl}_{2}$ (99.995 trace metal basis), TABH (98\%), and 1,2phenylenediamine (98\%) were purchased from SigmaAldrich. The hydrochloric acid solution (36.5\%) was purchased from Honeywell Chemicals. All manipulations involving water and air-sensitive chemicals were carried in a glovebox under an argon atmosphere. The degassing and reactions under inert atmosphere were carried out using standard Schlenk line techniques. Silica gel chromatography was performed on 230-400 mesh silica gel (Silicyl). Thin layer chromatography was performed using Merck $60 \mathrm{~F}_{254}$ silica/alumina gel plates. FTIR spectra were recorded on a PerkinElmer Frontier spectrometer equipped with PIKe GladiATR module. The solution-phase NMR spectra were recorded using a Bruker Avance III $500 \mathrm{MHz}$ spectrometer using deuterated solvents. The solid-state CP MAS ${ }^{13} \mathrm{C}$ NMR spectrum was recorded using a Bruker Avance Neo $400 \mathrm{MHz}$ spectrometer using $7 \mathrm{kHz}$ spinning rate and with a $5.0 \mathrm{~s}$ relaxation delay. The NMR spectra were calibrated based on the deuterated solvent peak. The XRD patterns were obtained using a STOE STADI-P system using $\mathrm{Cu} K \alpha 1$ incident beam. The samples were scanned between $2^{\circ}$ and $60^{\circ}$ of $2 \theta$. The XPS measurements were carried out using a PHI VersaProbe II scanning XPS microprobe (Physical Instruments AG, Germany). Analysis was performed using a monochromatic Al K $\alpha$ X-ray source of $24.8 \mathrm{~W}$ power with a beam size of $100 \mu \mathrm{m}$. The spherical capacitor analyzer was set at $45^{\circ}$ take-off angle with respect to the sample surface. The pass energy was $46.95 \mathrm{eV}$ yielding a full-width at halfmaximum of $0.91 \mathrm{eV}$ for the $\mathrm{Ag} 3 \mathrm{~d} 5 / 2$ peak. Curve fitting was performed using the fityk software. The EA was performed on a ThermoFischer Flash 2000 analyzer using BBOT as a reference standard. TGA was performed on a Mettler-Toledo TGA/DSC 3+ instrument using standard $70 \mu \mathrm{L}$ alumina and $40 \mu \mathrm{L}$ aluminium crucibles. The flow rate of the respective gas (air or $\mathrm{N}_{2}$ ) was set to $20 \mathrm{sccm}$ and the heating rate was set to $3 \mathrm{~K} / \mathrm{min}$. Nitrogen, $\mathrm{CH}_{4}$ and $\mathrm{CO}_{2}$ sorption was measured at 77 and $273 \mathrm{~K}$ using Micromeritics 3Flex instrument, after evacuation of the samples at $363 \mathrm{~K}$ for $24 \mathrm{~h}$. The pore size distribution was determined via NLDFT. The field emission SEM images were obtained on a ThermoFischer Scios 2-focused ion beam scanning electron microscope using $3.0 \mathrm{kV}$ accelerating voltage and $0.40 \mathrm{nA}$ of current. The samples were coated with $5.0 \mathrm{~nm}$ gold using a Cressington 208HR sputter coater in order to avoid charging.

\section{Procedures}

The octaketone was prepared according to the previously reported literature procedure. ${ }^{13-15}$ The 3D-mPOP was synthesized by the ionothermal method using a eutectic salt mixture composed of $\mathrm{NaCl}, \mathrm{KCl}$, and $\mathrm{ZnCl}_{2}$ salts. ${ }^{16}$ The mixture of $79.3 \mathrm{mg}$ of octaketone $(0.15 \mathrm{mmol}), 85.2 \mathrm{mg}$ of TABH (0.30 mmol), $18.4 \mathrm{mg}$ of $\mathrm{NaCl}(0.315 \mathrm{mmol}), 59.3 \mathrm{mg}$ of $\mathrm{KCl}(0.795 \mathrm{mmol})$, and $169.7 \mathrm{mg}$ of $\mathrm{ZnCl}_{2}(1.245 \mathrm{mmol})$ was finely ground in a mortar. The resulting solid mixture was then transferred into a Pyrex ampule $(18 \mathrm{~mL})$ and evacuated under vacuum for 45 min before being flamesealed. The ampule was heated in an oven at $250{ }^{\circ} \mathrm{C}$ for $48 \mathrm{~h}$. After the completion of the polymerization, the contents of the ampule were washed with acetone $(100 \mathrm{~mL})$, THF $(100 \mathrm{~mL})$, methanol $(100 \mathrm{~mL})$, and water, respectively. Finally, the polymer was stirred in $500 \mathrm{~mL}$ of a $0.1 \mathrm{M} \mathrm{HCl}$ solution for $5 \mathrm{~d}$ at RT before subsequent purification by Soxhlet extraction using methanol to yield $65.6 \mathrm{mg}$ (66.2\%) of 3D-mPOP as a black powder.

The model compound was synthesized using the same procedure in $85 \%$ yield as a brown powder. ${ }^{14}$

${ }^{1} \mathrm{H} \mathrm{NMR}\left(\mathrm{CDCl}_{3}, 500 \mathrm{MHz}\right): \delta 8.18(\mathrm{dd}, J=5.8,3.2 \mathrm{~Hz}, 8$ H), 7.79 (dd, $J=5.8,3.2 \mathrm{~Hz}, 8 \mathrm{H}$ ), 7.59 (s, 16H) ppm.

${ }^{13} \mathrm{C} \mathrm{NMR}\left(\mathrm{CDCl}_{3}, 125 \mathrm{MHz}\right): \delta 152.40,141.62,139.36$, $130.65,130.35,129.53 \mathrm{ppm}$.

\section{Funding Information}

This project was funded by the Swiss National Science Foundation (SNF) (grant 200021-175947 to A.C.), the donors of the American Chemical Society Petroleum Research Fund (grant ND-58919 to O.Š.M.), the Welch Foundation (grant E1768 to O.Š.M.), and the US National Science Foundation (grant DMR-1904998 to O.Š.M.).

\section{Supporting Information}

Supporting Information for this article is available online at https://doi.org/10.1055/a-1512-5753.

\section{Primary Data}

Crystal structure data for octaketone have been deposited with the Cambridge Crystallographic Data Centre under code CCDC-2069402.

\section{References}

(1) Nandi, M.; Uyama, H. Chem. Rec. 2014, 14, 1134.

(2) Wang, W.; Zhou, M.; Yuan, D. J. Mater. Chem. A 2017, 5, 1334.

(3) (a) Patel, H. A.; Karadas, F.; Canlier, A.; Park, J.; Deniz, E.; Jung, Y.; Atilhan, M.; Yavuz, C. T. J. Mater. Chem. 2012, 22, 8431. (b) Jin, Y.; Voss, B. A.; Jin, A.; Long, H.; Noble, R. D.; Zhang, W. J. Am. Chem. Soc. 2011, 133, 6650. (c) Rabbani, M. G.; Reich, T. E.; Kassab, R. M.; Jackson, K. T.; El-Kaderi, H. M. Chem. Commun. 2012, 48, 1141. (d) Patel, H. A.; Je, S. H.; Park, J.; Chen, D. P.; Jung, Y.; Yavuz, C. T.; Coskun, A. Nat. Commun. 2013, 4, 1357. (e) Dawson, R.; 
Adams, D. J.; Cooper, A. I. Chem. Sci. 2011, 2, 1173. (f) Jin, Y.; Voss, B. A.; McCaffrey, R.; Baggett, C. T.; Noble, R. D.; Zhang, W. Chem. Sci. 2012, 3, 874.

(4) D’Alessandro, D. M.; Smit, B.; Long, J. R. Angew. Chem. Int. Ed. 2010, 49, 6058

(5) (a) Buyukcakir, O.; Seo, Y.; Coskun, A. Chem. Mater. 2015, 27, 4149. (b) Pederson, A. M.-P.; Gibson, H. W.; Slebodnick, C. Supramol. Chem. 2020, 32, 452. (c) Romano, V. J.; Macartney, D. H. Supramol. Chem. 2018, 31, 172.

(6) (a) Byun, Y.; Je, S. H.; Talapaneni, S. N.; Coskun, A. Chem. Eur. J. 2019, 25, 10262. (b) Byun, Y.; Coskun, A. Angew. Chem. Int. Ed. 2018, 57, 3173. (c) Chavez, A. D.; Smith, B. J.; Smith, M. K.; Beaucage, P. A.; Northrop, B. H.; Dichtel, W. R. Chem. Mater. 2016, $28,4884$.

(7) (a) Lu, W.; Yuan, D.; Zhao, D.; Schilling, C. I.; Plietzsch, O.; Muller, T.; Bräse, S.; Guenther, J.; Blümel, J.; Krishna, R.; Li, Z.; Zhou, H.-C. Chem. Mater. 2010, 22, 5964. (b) Charles, C. D.; Bloch, E. D. Supramol. Chem. 2019, 31, 508.

(8) (a) Dai, D.; Yang, J.; Zou, Y.-C.; Wu, J.-R.; Tan, L.-L.; Wang, Y.; Li, B.; Lu, T.; Wang, B.; Yang, Y.-W. Angew. Chem. Int. Ed. 2021, 60, 2. (b) Li, G.; Zhang, B.; Yan, J.; Wang, Z. Chem. Commun. 2016, 52, 1143. (c) Skorjanc, T.; Shetty, D.; Trabolsi, A. Chem 2021, 7, 882. (d) Shetty, D.; Jahović, I.; Skorjanc, T.; Erkal, T. S.; Ali, L.; Raya, J.; Asfari, Z.; Olson, M. A.; Kirmizialtin, S.; Yazaydin, A. O.; Trabolsi A. ACS Appl. Mater. Interfaces 2020, 12, 43160. (e) Byun, Y.; Xie, L. S.; Fritz, P.; Ashirov, T.; Dincă, M.; Coskun, A. Angew. Chem. Int. Ed. 2020, 59, 15166. (f) Delente, J. M.; Umadevi, D.; Byrne, K.; Schmitt, W.; Watson, G. W.; Gunnlaugsson, T.; Shanmugaraju, S. Supramol. Chem. 2020, 32, 508.

(9) (a) Zhou, T.; Zhao, Y.; Choi, J. W.; Coskun, A. Angew. Chem. Int. Ed. 2019, 58, 16795. (b) Kim, J.; Elabd, A.; Chung, S.-Y.; Coskun, A.; Choi, J. W. Chem. Mater. 2020, 32, 4185.

(10) (a) Talapaneni, S. N.; Kim, D.; Barin, G.; Buyukcakir, O.; Je, S. H.; Coskun, A. Chem. Mater. 2016, 28, 4460. (b) Chen, X.; Wu, L.; Yang, H.; Qin, Y.; Ma, X.; Li, N. Angew. Chem. Int. Ed. 2021, 60, 1.
(11) McHale, C. M.; Stegemoller, C. R.; Hashim, M. I.; Wang, X.; Miljanić, O. Š. Cryst. Growth Des. 2019, 19, 562.

(12) Eisterhold, A. M.; Puangsamlee, T.; Otterbach, S.; Bräse, S.; Weis, P.; Wang, X.; Kutonova, K. V.; Miljanić, O. Š. Org. Lett. 2021, 23, 781.

(13) Wang, Y.-T.; McHale, C.; Wang, X.; Chang, C.-K.; Chuang, Y.-C.; Kaveevivitchai, W.; Miljanić, O. Š.; Chen, T.-H. Angew. Chem. Int. Ed. 2021, in press; Doi: 10.1002/ange.202102813.

(14) Hahn, S.; Alrayyani, M.; Sontheim, A.; Wang, X.; Rominger, F.; Miljanić, O. Š.; Bunz, U. H. F. Chem. Eur. J. 2017, 23, 10543.

(15) (a) Alrayyani, M.; Miljanić, O. Š. Chem. Commun. 2018, 54, 11989. (b) Ji, Q.; Le, H. T. M.; Wang, X.; Chen, Y.-S.; Makarenko, T.; Jacobson, A. J.; Miljanić, O. Š. Chem. Eur. J. 2015, 21, 17205.

(16) Maschita, J.; Banerjee, T.; Savasci, G.; Haase, F.; Ochsenfeld, C.; Lotsch, B. V. Angew. Chem. Int. Ed. 2020, 59, 15750.

(17) Larkin, P. Infrared and Raman Spectroscopy: Principles and Spectral Interpretation. Elsevier Science: Amsterdam, 2011.

(18) Mao, M.; Luo, C.; Pollard, T. P.; Hou, S.; Gao, T.; Fan, X.; Cui, C.; Yue, J.; Tong, Y.; Yang, G.; Deng, T.; Zhang, M.; Ma, J.; Suo, L.; Borodin, O.; Wang, C. Angew. Chem. Int. Ed. 2019, 58, 17820.

(19) Briggs, D. Handbook of X-ray Photoelectron Spectroscopy. Perkin-Elmer Corp. Physical Electronics Division: Minnesota, 1981.

(20) Brunauer, S.; Emmett, P. H.; Teller, E. J. Am. Chem. Soc. 1938, 60, 309.

(21) Wang, P.; Zhang, G.; Chen, W.; Chen, Q.; Jiao, H.; Liu, L.; Wang, X.; Deng, X. ACS Omega 2020, 5, 23460.

(22) (a) Bardestani, R.; Patience, G. S.; Kaliaguine, S. Can. J. Chem. Eng. 2019, 97, 2781. (b) Thommes, M. Chem. Ing. Tech. 2010, 82, 1059.

(23) Othman, M.; Tan, S.; Bhatia, S. Microporous Mesoporous Mater. 2009, 121, 13.

(24) Sekizkardes, A. K.; Culp, J. T.; Islamoglu, T.; Marti, A.; Hopkinson, D.; Myers, C.; El-Kaderi, H. M.; Nulwala, H. B. Chem. Commun. 2015, 51, 13393.

(25) Buyukcakir, O.; Je, S. H.; Park, J.; Patel, H. A.; Jung, Y.; Yavuz, C. T.; Coskun, A. Chem. Eur. J. 2015, 21, 15320. 